\title{
Wrestling with Outcomes: The New Zealand Experience
}

\section{David Webber}

$\mathrm{T}$ hroughout the 1990s public finance officials from many countries, industrialised and developing, beat a path to the door of the New Zealand public sector to examine and assess its reforms in public management. Although there were numerous dimensions to these reforms (see Scott, 1996; Boston et al., 1996; and Schick, 1996) 'output budgeting' was undoubtedly one of the more interesting and innovative components. While it remains a core element in the structure and conduct of the budget process in 2004, an increasing focus on outcomes is significantly eroding the purity of this approach.

Since the mid-1990s at least, international experience and experimentation with new methods of government budgeting and expenditure management have also progressed, both towards and away from the New Zealand output-based approach. 'Performance Budgeting' — an increasingly broad term that now describes almost any approach or methodology that embodies a significant focus on results (including output budgeting) - is gaining increased acceptance. The basic argument for downplaying the role of outputs, while giving increased attention to outcomes, is well-summarised by Brumby and Robinson (2004:7):

A strong argument can be advanced for outcome-focused performance budgeting. Outcomes are the intended effects of government programs, whereas outputs - the goods or services delivered by government are the means of achieving those outcomes. It can therefore be argued that outcomes are what really matters, and that to focus too much upon outputs in a performance budgeting system is to run the risk of focusing too little upon the effectiveness and quality of services. ... Nevertheless, it can be argued that outputs must have a central role in a workable form of performance budgeting.

Recent developments in public sector budgeting in New Zealand fully reflect this search for a 'more balanced' focus. Indeed, considerable resources have been expended by both Treasury and the State Services Commission (SSC) to help departments achieve this (unspecified) balance and, in New Zealand's case at least, to try to reconcile the serious methodological uncertainties and institutional ambivalence that accompanies it. There have been significant gains and losses along the way.

David Webber is principal of the Economics and Strategy Group, a New Zealand-based consulting firm. 


\section{The Problems with Outputs}

The shift from an output to an outcomes focus in public expenditure management in New Zealand has occurred progressively over the last 4-5 years. It arose largely from two factors. The first was political. The 1999 elections brought in a Labourled coalition government determined to roll back some of the policy reforms of the previous 15 years, including selected aspects of the 'new public management' model. However, from about 1997, the essentially political argument that Government should be more proactive in the economy was not entirely separated from a growing technocratic perception that output budgeting had failed to ensure that government departments gave sufficient attention to the results of their policy interventions. Although the subsequent shift was arguably more a bureaucratic initiative than a political one, it was an integral part of a wider response by central agencies to the (largely unspecified) demands of a new government for different and more effective approaches to public sector management.

The legislative basis for New Zealand's output budgeting model was established primarily by the Public Finance Act 1989 (PFA). However, departmental experience with budgeting by outputs over the subsequent ten years had revealed a number of shortcomings. Perhaps the most obvious of these concerned the linkages established in the PFA between the accountability of public sector departments and agencies for outputs and ministerial responsibility for determining outcomes. Although some ministers took a conscientious approach to determining and monitoring their policy outcomes, this separation of responsibilities became a key factor in the unsatisfactory linkages between outputs and the intended impacts of spending programs. It was accompanied by a growing consensus in the domestic public management research literature that 'a key weakness in the current regime is the lack of information on the effectiveness of the public sector' (Petrie and Webber, 2001:para 119).

One initiative to address this problem, 'Key Result Areas', had been largely abandoned by the late 1990s, despite the fact it had succeeded in some respects in drawing departments' attention to the importance of the relationship between the design of their interventions and the expected, or intended, policy impacts.

Lack of departmental performance and attention to the impacts of public policies were not the only perceived shortcomings of the output-based approach. Problems also arose from the legislative requirement for departmental votes to be comprised of 'Output Classes' (defined effectively as groups of 'similar outputs'). In practice, similarity of outputs has not provided a meaningful basis for organising departmental expenditure operations, much less for effective parliamentary scrutiny and debate of expenditures. On this latter point, there is some evidence that these somewhat obscure categories of expenditure contributed to waning ministerial understanding of, and interest in, the detailed spending activities of their departments (Economics and Strategy Group, 2003).

As a result, the definition and composition of Output Classes across the public sector have shifted in recent years towards more management-related criteria. However, even within votes, few output classes are now based on 
consistent criteria and only some provide a meaningful indication to Parliament or the public of the expenditure purpose or intended impact.

At the operational level, weaknesses in the output model also contributed to a gradual devaluation of its status as a budgeting innovation, in New Zealand and internationally. Examples included the difficulty in reaching meaningful and measurable definitions of 'outputs' and 'output performance' in significant areas of departmental administration, such as policy advice or ministerial servicing. This was accompanied by increasing frustration in some departments with the resource demands and perceived inconsistencies in the conduct of 'output pricing' reviews - that is, formal procedures for establishing and reviewing the 'prices' to be used by departments for costing (predominantly non-market priced) outputs.

Notwithstanding these concerns, there is broad agreement that the overall efficiency of government improved substantially as a result of the public management reforms and that the strong focus on requiring departments to define and cost their outputs had been a significant contributor to the gains. However, the effects of a greater international focus on performance issues, combined with arguments for greater attention to outcomes by well-qualified commentators and advisers, such as Boston et al (1999), Controller and Auditor-General (1999), and Schick (1996) were formidable. The SSC too was pressing for the adoption by departments of a more 'strategic management' approach. By 2001, it was clear that some modifications to the output focus were both desirable and inevitable.

\section{The 'Review of the Centre'}

Many of the subsequent adjustments to the New Zealand model of public management in the past 3-4 years have their origins in the analysis and recommendations of the 'Review of the Centre' (RoC) - in essence a review by a committee of officials from central agencies with input from a small number of external advisers (SSC, 2001). Although this committee was established to review the roles and activities of the central agencies - hence the name - its focus shifted to much broader public management issues. In particular, its focus was on various shortcomings that had been identified in the public management model established by the reforms of the late 1980s. The RoC grouped these perceived problems into three main major categories: a lack of integration in the delivery of government services; associated fragmentation and lack of alignment within and between sector departments and agencies; and weaknesses in building and sustaining institutional capabilities and organisational culture.

The main thrust of the RoC's recommendations for modifying the budgeting and expenditure management process involved adding-on a much stronger results (outcomes) focus to the existing output-based model. It noted that the public management reforms of the late 1980s had 'hard-wired in an output-based management system' RoC (2001). The aim, therefore, was to soften this outputbased model rather than replace it with a new or different approach. However, it also argued that departments be required to build procedures and documents into their annual planning activities that would strengthen their internal strategic 
planning process. Importantly, it noted that these strategies should be aligned with outcomes to be identified by departments, in consultation with their ministers.

The RoC analysed the above problems with reference to recent innovations from international managerial journals and literature, but with little or no theoretical underpinning in public financial management. At no stage did the RoC analyse the strengths and weaknesses of the output model itself, nor describe how the proposed changes would fit within a coherent new expenditure framework. This incremental approach was effectively endorsed by the Minister of Finance in 2003 who stated that the legislation underpinning the output-based model did not require major amendment: 'Experience shows that the fundamentals of the two Acts (the State Sector Act 1988 and the PFA 1989) are sound' (Cullen, 2003).

The resultant RoC recommendations were arguably pragmatic, but noticeably lacked effective reconciliation of output and outcome concepts. The expenditure management process was thus modified with the addition of a series of planning and reporting requirements to the original output-based model, without a clear explanation of how expected improvements in policy outcomes would occur.

\section{Managing for Outcomes}

Since 2001, departments have received instructions and support for implementation of the RoC's recommendations through an intensive series of workshops and guidance materials under the 'Managing for Outcomes' (MfO) initiative. ${ }^{1}$ This has been a combined undertaking of the central agencies, principally The Treasury and the SSC, which did much of the work to guide and support departments in the uptake of this approach. Introduction of the MfO initiative has required departments to produce annual Statements of Intent (SOI) that emphasise a 'strategic outcomes framework'. An explicit consequence of this focus has been less reliance on the previous, narrower, output-based planning. The more explicit outcomes focus in planning is also to be reflected and reinforced by parallel adjustments in official departmental documents relating to ex post (performance) reporting. Proposed amendments to the PFA (currently before Parliament) will effectively cement these modifications into legislation.

Recent evaluation work on the uptake of MfO concepts and tools suggests that good progress has been made in some areas, especially in developing SOIs (see, for example Economics and Strategy Group, 2003). However, the absence of a clear and fully articulated model in which output and outcome concepts are effectively integrated in the budgeting and expenditure management process has generated particular difficulties for senior managers in many departments. In terms of Figure 1, it has presented departments with considerable challenges in linking the rationale for their spending operations with both appropriations (that is, relevance) and with impact assessment. Not surprisingly, the requirements to develop a meaningful 'intervention logic' and an effective structure for

1 A number of papers and guidance materials relating to this initiative are available at www.ssc.govt.nz/managing_for_outcomes. 
'performance measurement' have clearly emerged for all departments as the most difficult aspects of implementing the MfO initiative. The MfO model of expenditure management provides neither an inherent process, nor clear guidance, for making these critical linkages, but requires only that they should be made. ${ }^{2}$

Experience so far has generated a range of departmental-specific responses and practices that vary significantly in both content and merit (ibid). The development of a set of performance measures to provide an accurate assessment of progress or impact, especially where the specified outcomes are broad or ambitious, has been a common difficulty. It is no surprise that, as a result, some chief executives have pointed to the SSA 1988 to remind central agency officials that they (and their departments) are not accountable for achieving outcomes.

\section{Figure 1: Linking the Basic Components of the Expenditure Process}

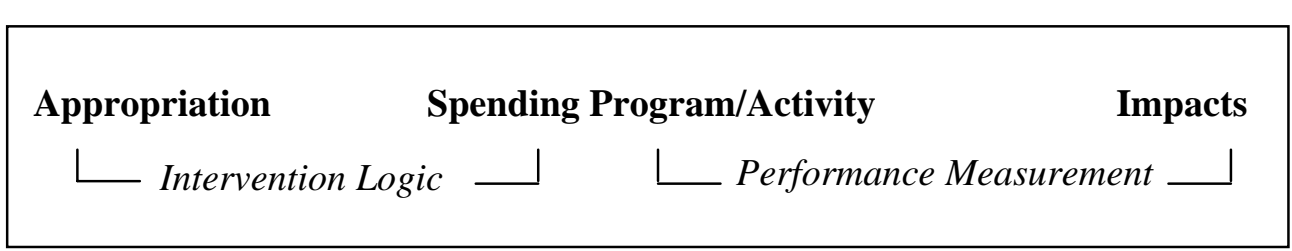

While many of the former requirements on output planning, specification and reporting remain, the precise roles and importance of both outputs and 'output classes' are much less clear, and fit less comfortably within this new framework. Currently proposed amendments to the PFA are, in effect, aimed at keeping and reconciling aspects of both models but fail to provide either conceptual or practical clarity on this issue. This approach was described by a central agency official as 'not wanting to throw the baby out with the bathwater'.

The lack of a formal and coherent framework for expenditure management may also have increased the difficulty in integrating other critical facets of improved public management. For example, a clear framework could have provided a recent review of evaluation activities within the public sector (SSC, 2003) with a better starting point for determining the likely contribution (where and in what form) of evaluations to the assessment and development of policy objectives and performance. Recommendations from that review (which supported the utility of evaluation capabilities, but left individual departments to determine the role, structures and methods) reflected, in part, the uncertainty surrounding the integration of output and outcome methodologies, including where performance evaluation could best contribute to policy development.

Finally, recent indications that some departments may also be considering realigning organisational structures on the basis of outcomes is a particular cause for concern. At no stage yet have any departments formulated a set of practical and

2 Early in the MfO development process there was an attempt to provide departments with a business-planning model for a more effective planning process. However, this was abandoned when the initial model failed to gain acceptance among the pilot agencies. 
achievable intended outcomes that could be said to provide a clear and consistent basis for expenditure management, much less functional alignment.

Whether the difficulties facing departments in adopting this new hybrid model of expenditure management are just teething problems or reflect deeper incompatibilities in design is not yet fully clear. Nevertheless, it can be argued that practical application of the new outcome-focused structure has proved difficult for central agencies to define and explain, and is proving difficult, and onerous, for departments to implement effectively.

\section{International Experience with Outcomes-Based Budgeting}

The New Zealand public sector has not been alone in recent years in struggling to achieve an effective application of outcome concepts. The Finance Committee of the Scottish Parliament recently commissioned an international survey of outcome budgeting experience to help to guide it in the possible introduction of these concepts (Flynn, 2001). The survey found sufficient support for the introduction of outcome statements in the design and presentation of appropriations, but cautioned the Finance Committee against having high expectations of what outcome setting could reliably add to the quality of resource allocation decisions.

For New Zealand, however, the key issue has involved how best to overlay an outcomes focus on an output budgeting model. Brumby and Robinson (2004:8) cite the British Public Service Agreement (PSA) system in this context:

When the system started off in 1998, most of the PSA targets were output targets. In the two subsequent rounds of PSA target setting, there has been a progressive and deliberate re-orientation towards outcomes, so that today most PSA targets are outcome rather than output targets. Nevertheless, outputs have not been forgotten. Service Delivery Agreements have been introduced at a more operational level, and these set targets for outputs which are intended to mesh together with the toplevel PSA outcome targets.

The fact that the United Kingdom started this process two or three years ahead of New Zealand may be encouraging. Although the authors do not comment on the success of the 'meshing' process so far, anecdotal reports suggest that a slightly messy, but perhaps more structured relationship has developed in some areas between the two sets of concepts and measures - albeit through a mostly ad hoc, experiential process. A similar process is now clearly occurring in New Zealand, but also without conclusive results.

These conservative assessments underline the fact that most countries engaged in outcome specification have experienced significant challenges. These include maintaining consistency in the definition of outcomes (in terms of the level at which outcome objectives are set), maintaining the feasibility and practicality of outcome targets (in the face of political pressure to aim higher), and 
identifying and maintaining well-specified outcome targets for long enough for meaningful performance measurement and policy assessment to occur.

Not surprisingly, the definition of an outcome - as opposed to other potential policy impacts - has tended to be wide and variable within and across departments and in some cases set at levels well outside the feasible reach, or direct policy influence, of the department. Within both the public and private sectors in New Zealand the identification of an 'outcomes focus' has already been coined as a trendy (but often insubstantial) indicator of the relevance of policy or research. There is also slow, but increasing, realisation in some parts of the public sector (for example, with regard to the targeting of welfare payments) that this year's policy problems are not infrequently last year's policy outcomes.

Policies often do not achieve what politicians or bureaucrats expected and the expenditure management framework needs to ensure that policy design can respond quickly, and appropriately, when needed. Too much emphasis on outcomes makes this more difficult if the government appears to be 'giving up' on a particular outcome statement. It is therefore critical that outcomes, or results, are defined at a level on which public policy may have a measurable impact.

In addition, significant insights from the international managerial literature and private sector management practices (especially on strategic management) have also been increasingly overlaid on the task of managing public finances. While each of these concepts and innovations may have added interest and richness to the subject, for most New Zealand Government departments at least, they have also added greater expectations, complexity and compliance demands.

It therefore seems reasonable to ask whether the public sector is still on track to achieving new and improved levels of effectiveness in public spending? Is there a risk that in pursuing an almost 'continuous improvement' approach (cycles of reform in effect) that the budgetary system that is developing in New Zealand lacks overall coherence, or even a basic managerial orientation? Does the current approach still embrace all that is fundamental to good budget management?

\section{The Fundamental Elements}

All budgetary and expenditure management systems — whether they are labelled (or have origins in) 'Program Budgeting', 'Performance Budgeting' or 'Outcome Budgeting' to name a few - are concerned with ensuring that public spending agencies use public funds effectively (that is, deliver value for money in implementing government policy). While economists may describe and assess this objective in terms of 'aggregate, allocative, and technical efficiency', most public sector employees simply see them in terms of 'appropriation', 'spending operations' (often 'service delivery'), and 'performance measurement'. However, it is often less well recognised that the efficacy of the system is determined by the quality of the interactions, or managerial linkages, between these components.

Different budgeting methodologies can and do give different emphasis to the various components, or connections, within this structure. The relative simplicity of the above objective for public expenditure understates the real difficulties in 
obtaining meaningful assurances of quality and integrity. In practice, the public relies heavily on various institutions, including Parliament as well as private commentators and non-government agencies, to monitor and where possible ensure the quality and effectiveness of the spending decisions and actions of the government. However, many of these institutions and observers have a tendency to focus on specific stages, or components of the financial management process. The ultimate value and quality of their analysis and reporting therefore depends on a management process that is not only clearly defined, but also effectively linked.

\section{Connecting Management Decisions}

As Figure 1 indicates, the fundamental elements of a public expenditure system are not complex. The challenges lie in linking the various components effectively. For government departments, uptake of the MfO initiative has imposed a strong (though not unreasonable) demand to rethink, formulate and articulate their 'intervention logic', and a supporting 'performance measurement framework', to a degree that was not required before. The eventual success of this evolving model of budget management will depend substantially on departments acquiring, or developing over time, the skills and capability to do this, including especially achieving an effective integration of output and outcomes concepts.

Another factor evident during the piloting stage is that the technical expertise required to develop a sophisticated and effective strategic and performance measurement framework for guiding management decisions requires skills that are not only in short supply in the wider public sector, but are often limited to even one or two individuals within the larger departments. Moreover, the operational environment and budget management needs of departments vary significantly and general guidance material cannot make the outcomes structure a readily applicable tool. Faced with this, much of the work required for outcomes specification and the associated documentation has been assigned to small groups of policy and strategy analysts within departments whose task it is to make the framework and performance measures 'fit' with departmental policies and operations.

There is a clear risk that ceding this responsibility to a very small number of specialists, or worse to out-sourced consulting expertise as has also occurred, will distance the process further from the day-to-day managerial and operational teams. A sound framework for managing public expenditures can be achieved only when it is fully understood by, and is effectively in the hands of, departmental budget managers. Many larger departments in particular must be constantly focused on the management and delivery of core programs and services that meet relatively simple, but invariably high, public expectations. While they can identify, assess and report back on the consequences of their activities, it is much more difficult to develop effective policies from objectives and statements based on longer-term outcomes (even assuming that modestly accurate and timely performance data are available). The Scottish study referred to above includes a powerful conclusion, from Swedish experience, that outcome data alone do not imply (or engender) a capacity to use those data to design more effective interventions. 
A further complication with practical application of the outcomes focus arises from the fact that a substantial majority of the spending activities of departments are on-going (baseline) policies and activities. New policies that provide an opportunity to focus first on outcomes (before detailed operations and organisational responsibilities are determined) occur infrequently, or at the margin of on-going departmental expenditure programs. It is no surprise that organisations which appear to have adopted the outcomes model most readily (for example, the Department of Corrections) are those whose mandate implies a relatively tightlyconstrained 'outcomes set', for example, secure confinement and reduced reoffending rates for prison inmates. Similarly, departments such as the Ministry of Fisheries appear able to apply an 'outcomes' focus more readily provided that this is constrained to quite specific resource management and monitoring functions.

In practice, the departments perceived to be more successful in applying the outcomes-based approach to date are those which are focusing on more narrowly defined targets - better described as results. Take away this more narrow focus (for example, by introducing broader industry development or improved societal welfare goals) and the task of specifying an outcomes-focussed intervention logic, with relevant performance measures, becomes problematic. So it is perhaps not surprising that the departments whose predominant output is ministerial 'policy advice', of which there are several in New Zealand, have generally had the greatest difficulty in developing a meaningful outcomes-based strategy and performance measurement framework (Economics and Strategy Group, 2003).

\section{Beyond Outputs and Outcomes}

The Managing for Outcomes initiative has undoubtedly succeeded in nudging most departments towards a more performance-oriented view of their activities. It has not, however, prompted this development in a way that guarantees an improvement in the quality and impact of government interventions. On the contrary, most departments have struggled to develop effective forms or expressions of intervention logic and performance measurement within the outcomes model. At the same time, some of the sharper accountability features of the previous output-based public management regime have been eroded.

Application of the outcomes-oriented approach has found many departments, especially those with a wider and more complex mandate, with insufficient skills or tools for this transition. An increased focus on results is desirable, but this needs to be implemented in ways which involve retaining the strengths of the output budgeting model. Successful application of the results focus also requires a methodology that better enables departments to achieve effective integration of policy design, operations and service delivery and impact assessment.

Figure 2 attempts a more detailed exposition of the nature and composition of the budgeting and expenditure management process, including a more integrated expression of the core relationships. Moreover, it links the contribution from each of these functions to a range of public management objectives invariably present in most well developed public administrations. It demonstrates that operational 
activities sit at the centre of departmental management and resource allocation decisions and that the impacts of these decisions may be measured and assessed in varying ways, and at varying distances, from the program delivery function.

Outcomes are shown as being clearly at the end of this process. For this reason, they may often be the most difficult point from which to work back to improved policy and operational decisions, much less to an expression of the department's intervention logic and its funding (that is, appropriation) criteria. Furthermore, Figure 2 indicates the linkages between the essential components of the expenditure management process in a way that meets parallel and specific demands for 'relevance', 'efficiency', 'effectiveness' and 'sustainability'.

Figure 2: The Expenditure Management Process ${ }^{3}$

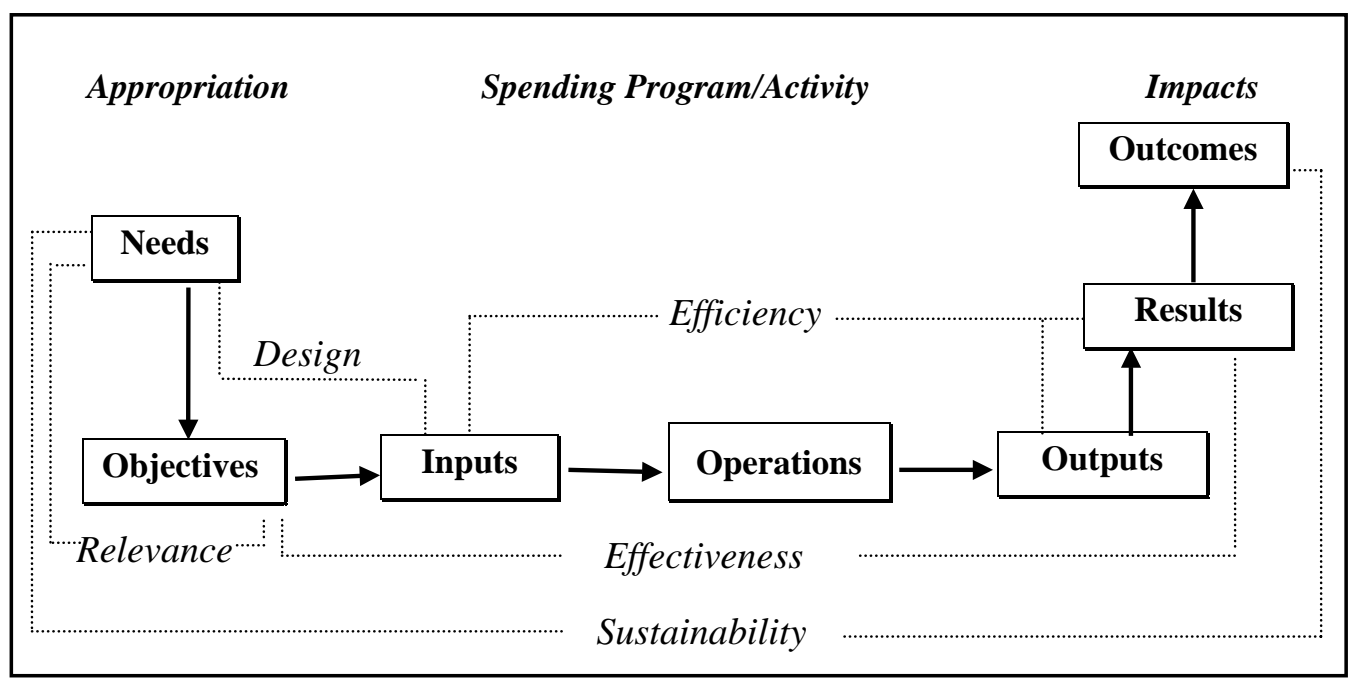

\section{Program Design and Delivery: The Essence of Intervention}

The difficult task of determining intervention logic is best undertaken in the course of designing and developing a department's operational programs and activities. This is the point at which the broad policy objectives implied by a government's appropriation decisions are converted into practical operations and services. It is at this point that a department must make its policy objectives explicit and link them to specific spending decisions that will generate quantifiable outputs. Determining the department's intervention logic cannot be separated

3 Figure 2 is adapted from an idea in a European Community (2000) working paper on designing evaluations. The power to design public policy evaluation based on the dotted relationships presented across the public expenditure management process is an important feature of this Figure, but is not fully elaborated in this paper. 
from the process of determining what operational activities those interventions may require, including their respective chances of success.

This approach of starting from the integration of policy objectives and the design of programs is arguably much more consistent with organisational structures and the assignment of managerial and budget responsibilities than an outcomes-first approach. In particular, it avoids one of the problems with an outcomes-based approach that managers may become isolated from the planning process and therefore unable to closely, or usefully, relate their activities to specific outcome targets. ${ }^{4}$ It also helps to avoid the problems that may arise from an almost exclusive focus on outputs where managers and operational staff fail to identify with a comparatively sterile description of purpose and incomplete, or unchallenging, measures of performance and accountability.

Once the core rationale for the department's intervention has been established through this linkage of policy objectives and program operations, it is a relatively simple process to work outwards (in both directions) towards a preferred structure of appropriation and performance measurement needs, without losing any of the benefits of either the outputs or outcomes-based concepts.

\section{Appropriations}

The organising principle for budget appropriation in New Zealand has traditionally been institutional. It is only by clearly assigning public monies to specific organisations, within which managerial and financial accountabilities are clearly identified, that full accountability can be maintained. Attempts elsewhere to appropriate by outcome or similar organising principles have almost always given way to a need for improved transparency and accountability through at least de facto assignment to specific institutions. The propensity to appropriate budget funds on the basis of 'joint' or 'cross-sectoral' outcomes should be resisted for similar reasons. Where common outcomes are identified, they can be pursued much more effectively, and with greater transparency and accountability, through coordinated departmental management and operational or service delivery, mechanisms.

Effective parliamentary scrutiny and control of expenditures requires that aggregate appropriations in most cases need to be broken down into smaller categories of expenditure. New Zealand's current sub-appropriations, or Output Classes, are no longer effective within the present expenditure management framework. (In fact, definitional problems have always prevented them from becoming a satisfactory mechanism for sub-grouping an appropriation.) These Output Classes need to be replaced in favour of appropriations that are broken down on a functional, programmatic basis - that is, programs with broadly related expenditure objectives, or common goals that are understandable to, and reviewable by, the Parliament. Such programs may, of course, still be able to be

4 It is worth noting in this respect that one or two departments that have made considerable efforts to involve line managers and operational staff in the initial outcomes planning process have commented that they hope that such extensive consultation will not be necessary in future years. 
aligned with a common specific outcome, or sub-set of outcomes, within the sector.

\section{Outputs}

Figure 2 also reveals a clear and logical hierarchy of performance measures that flow upwards from outputs to results and finally outcomes. It shows that outputs have a special and important role within any performance measurement framework by enabling departments to express their policy decisions and program design in terms of practical and transparent purchases, or provision, of goods and services. New Zealand's experience with outputs argues strongly for their retention as an integral part of the expenditure management framework. However, this role should be (a) as a key accountability device ('What were public funds actually spent on?') and, (b) as an effective basis for establishing and monitoring efficiency issues. For some departments, however, not all activities can be usefully expressed or monitored in output terms.

\section{Results}

Policy and program interventions are, or should be, designed to achieve a clear and measurable set of results that sit between outputs and outcomes. Results should be directly linked to program objectives as the direct consequences or impacts of the expenditure. They differ markedly from outcomes in two main respects: their achievement is totally or very substantially the result of the policy or program and this impact or improvement is evident and measurable within a policy-relevant period. As Figure 2 indicates, this is the only level at which it is feasible and meaningful to assess the effectiveness of interventions. If relevant and measurable results cannot be articulated, then the policy or program design needs to be revisited. As with outputs, the measurement of results should for most programs be limited to a small number (2-5) of critical indicators.

\section{Outcomes}

The budgeting and expenditure management framework proposed in this paper includes a continuing, albeit adjusted, role for outcomes. Their most important function is to indicate the sustainability of the range of government expenditure policies embodied in current appropriations. The sustainability objective is best measured by the degree to which government policies collectively — that is, taking into account the interventions of all public agencies within the sector, plus the incentives or controls applied to private behaviour especially through regulation and enforcement - have a positive, or negative, longer-term impact on societal outcomes.

Monitoring of these outcomes, most likely at the sectoral level for most departments, should therefore enable departments to advise the government on the degree to which the total sum of their policies and operations may be contributing to positive change. Conversely, measurement of outcomes rarely provides a 
particularly useful indicator of either the efficiency or effectiveness of individual agencies or expenditure programs and ought not to be used for this purpose.

This configuration of the outcomes focus implies a different, but no lesser, role from that currently assigned to them in the MfO initiative. Indeed, some departments with comparatively limited operational functions — such as policy ministries in Health or Research, Science \& Technology — are now (after some initial missteps) recognising the need to assign outcomes to this broader (that is, sectoral) performance measurement role. Other ministries need to follow this example, ensuring in the process that outcomes are expressed as sector, not departmental, goals. This implies that outcomes - and outcomes measurement - should have only a background role in assessing the effectiveness of policies and therefore in the accountability framework of the department.

\section{Evaluation}

Finally, it should be evident that this framework makes it easier to assign clear objectives and an explicit focus for the evaluation of public expenditures. The performance measurement hierarchy in Figure 2 not only identifies the various types of evaluation - any one or more of which may be appropriate for different purposes - but links these concerns to the corresponding form and level of objectives. From here, it should also be possible to establish more clearly the appropriate boundaries of institutional performance and accountability.

\section{Conclusion}

An output-based budgeting framework brought much-needed specificity and accountability to the spending operations of the New Zealand public sector. However, it was perceived as failing to generate sufficient attention to, or improvement in, the impacts of government policies. Requirements for an increased focus on outcomes have been directed at these problems, but have created many difficult challenges for most departments. The new Managing for Outcomes approach risks eroding clear understanding of the determinants of policy effectiveness and may have already removed some of the sharp edges from organisational accountability. These developments have potentially serious implications for the quality and integrity of public spending. Sound management of public finances should be pursued by moving beyond outputs and outcomes to a clearly articulated and effectively integrated expenditure management framework. This will be one that puts policy design and program delivery back at the core of the expenditure management process and binds them to a set of clear, modest and achievable policy objectives and intended results.

\section{References}

Boston, J. (1999), 'The New Zealand Model of Public Management: A Brief Assessment', paper prepared for a Summit on 'Process of Governance and the Role and Place of the Individual, Community and Markets’, Wellington, 31 May. 
Boston, J., J. Martin, J. Pallot and P. Walsh (1996), Public Management: The New Zealand Model, Oxford University Press, Melbourne.

Brumby, J. and M. Robinson (2004), 'Performance Budgeting, an Overview', paper prepared for IMF and Brazilian Ministry of Planning, Budget and Management seminar: 'International Seminar on Performance Budgeting’, Brasilia, March 2004.

Controller and Auditor-General (1999), Report of the Controller and Auditor-General: Third Report for 1999, Parliamentary Paper B.29[99c], Office of the Auditor-General, Wellington.

Cullen, M. (2003), ‘Address to the Public Sector Conference', Wellington, 19 August.

Economics and Strategy Group (2003), 'Departmental Uptake of the Managing for Outcomes Initiative', Independent evaluation undertaken for the 'Managing for Outcomes Steering Group’, August, available at: www.ssc.govt.nz/departmental-uptake-mfo.

European Commission (2000), 'Indicators for Monitoring and Evaluation: An Indicative Methodology’, Working Paper 3, Directorate-General XVI, Regional Policy and Coordination, Brussels.

Flynn, N. (2001) 'Moving to Outcome Budgeting', Paper commissioned for the Finance Committee by the Scottish Parliament Research and Information Group, available at: www.scottish.parliament.uk/S1/official_report/cttee/finance.

Petrie, M. and D. Webber (2001), 'Review of Evidence on Broad Outcome of Public Sector Management Regime', Treasury Working Paper 01/06, available at: www.treasury.govt.nz/working-papers.

Schick, A. (1996), 'The Spirit of Reform: Managing the New Zealand State Sector in a Time of Change', report to the State Services Commission, Wellington.

Scott, G. (1996), 'Government Reform in New Zealand', IMF Occasional Paper, Washington DC.

State Services Commission (2002), 'Report of the Advisory Group on the Review of the Centre', Presented to the Ministers of State Services and Finance, November 2001, available at: www.ssc.govt.nz.

State Services Commission (2003), 'Doing the Right Things and Doing Them Right Improving Evaluative Activity in the New Zealand State Sector', Published by the State Services Commission in conjunction with The Treasury, available at: www.ssc.govt.nz.

Webber, D. (2004), 'Managing the Public’s Money: From Outputs to Outcomes — and Beyond' presented to the New Zealand Association of Economists Conference, Wellington, 30 June, also to appear in OECD Journal on Budgeting 4(2), 2005.

The author gratefully acknowledges detailed comments by a referee and an editor. 